\title{
Processes and Properties of Ionic Liquid-Modified Nanofiller/Polymer Nanocomposites-A Succinct Review
}

\author{
Ahmad Adlie Shamsuri ${ }^{1, *(\mathbb{D})}$, Siti Nurul Ain Md. Jamil ${ }^{2,3, * \mathbb{C}}$ and Khalina Abdan ${ }^{1, *}$ \\ 1 Laboratory of Biocomposite Technology, Institute of Tropical Forestry and Forest Products, \\ Universiti Putra Malaysia, Serdang UPM 43400, Selangor, Malaysia \\ 2 Department of Chemistry, Faculty of Science, Universiti Putra Malaysia, \\ Serdang UPM 43400, Selangor, Malaysia \\ 3 Centre of Foundation Studies for Agricultural Science, Universiti Putra Malaysia, \\ Serdang UPM 43400, Selangor, Malaysia \\ * Correspondence: adlie@upm.edu.my (A.A.S.); ctnurulain@upm.edu.my (S.N.A.M.J.); \\ khalina@upm.edu.my (K.A.)
}

Citation: Shamsuri, A.A.; Jamil,

S.N.A.M.; Abdan, K. Processes and Properties of Ionic Liquid-Modified Nanofiller/Polymer

Nanocomposites-A Succinct Review. Processes 2021, 9, 480. https://

doi.org/10.3390/pr9030480

Academic Editor:

Shaghayegh Hamzehlou

Received: 27 January 2021

Accepted: 7 February 2021

Published: 8 March 2021

Publisher's Note: MDPI stays neutral with regard to jurisdictional claims in published maps and institutional affiliations.

Copyright: (C) 2021 by the authors Licensee MDPI, Basel, Switzerland. This article is an open access article distributed under the terms and conditions of the Creative Commons Attribution (CC BY) license (https:// creativecommons.org/licenses/by/ $4.0 /)$

\begin{abstract}
Ionic liquids can typically be synthesized via protonation, alkylation, metathesis, or neutralization reactions. The many types of ionic liquids have increased their attractiveness to researchers for employment in various areas, including in polymer composites. Recently, ionic liquids have been employed to modify nanofillers for the fabrication of polymer nanocomposites with improved physicochemical properties. In this succinct review, four types of imidazolium-based ionic liquids that are employed as modifiers—specifically alkylimidazolium halide, alkylimidazolium hexafluorophosphate, alkylimidazolium tetrafluoroborate, and alkylimidazolium bistriflimide-are reviewed. Additionally, three types of ionic liquid-modified nanofiller/polymer nanocompositesnamely ionic liquid-nanofiller/thermoplastic nanocomposites, ionic liquid-nanofiller/elastomer nanocomposites, and ionic liquid-nanofiller/thermoset nanocomposites-are described as well. The effect of imidazolium-based ionic liquids on the thermo-mechanico-chemical properties of the polymer nanocomposites is also succinctly reviewed. This review can serve as an initial guide for polymer composite researchers in modifying nanofillers by means of ionic liquids for improving the performance of polymer nanocomposites.
\end{abstract}

Keywords: ionic liquid; nanofiller; polymer nanocomposite; thermal; mechanical; chemical

\section{Introduction}

Recently, the employment of ionic liquids in green chemical technology has grown because of the environmental responsiveness and growth of the sustainable chemical industry. Ionic liquids are liquid salts that generally possess a lower melting point than the boiling point of water. They also possess a very low vapor pressure, resulting in them being non-volatile. The recyclability of ionic liquids has led them to be regarded as an environmentally benign solvent [1]. Furthermore, ionic liquids possess intriguing solvent properties, such as non-flammability, high polarity, good electrical conductivity, high thermal stability, and good solubility with many organic solvents, including water. They also have the ability to dissolve most organic and some inorganic materials, as well as biopolymers. Additionally, ionic liquids can be custom made, with properties corresponding to the requirements of the application. They can also be used as cationic surfactants if they have a long alkyl chain $\left(\geq C_{10}\right)$ [2].

Polymer nanocomposites are polymers that incorporate nanometer-scale fillers (usually called nanofillers) [3]. The modification of nanofillers using ionic liquids is a promising process in the fabrication of multifunctional polymer nanocomposites. In various types of ionic liquids, imidazolium-based ionic liquids with distinct oppose anions are regularly employed for modification of nanofillers. This was due to their effectiveness in a wide 
variety of chemical structures. Table 1 shows examples of imidazolium-based ionic liquids employed for modification of nanofillers. It can be observed that some ionic liquids possess similar alkylimidazolium cations with different counter anions; therefore, in this concise review, they have been classified into four types, namely alkylimidazolium halide, alkylimidazolium hexafluorophosphate, alkylimidazolium tetrafluoroborate, and alkylimidazolium bistriflimide. This classification is made since the ionic liquids must undergo distinct preparation processes with different counter anions.

Table 1. Examples of imidazolium-based ionic liquids employed for modification of nanofillers.

\begin{tabular}{|c|c|c|}
\hline Imidazolium-Based Ionic Liquid & Abbreviation & References \\
\hline 1-Allyl-3-methylimidazolium chloride & {$[\mathrm{Amim}][\mathrm{Cl}]$} & {$[4-7]$} \\
\hline 1-(3-Aminopropyl)-2-methyl-3-butylimidazole bromide & [Apmbim] $[\mathrm{Br}]$ & [8] \\
\hline 1-(3-Aminopropyl)-3-methylimidazolium bromide & {$[$ Apmim] $[\mathrm{Br}]$} & {$[8,9]$} \\
\hline 1-Butyl-3-methylimidazolium chloride & {$[\mathrm{Bmim}][\mathrm{Cl}]$} & [10] \\
\hline 1-Benzyl-3-methylimidazolium chloride & {$[\mathrm{Bzmim}][\mathrm{Cl}]$} & [11-16] \\
\hline 1-Decyl-3-methylimidazolium bromide & {$[\mathrm{Dmim}][\mathrm{Br}]$} & [17] \\
\hline 1-Decyl-3-methylimidazolium chloride & {$[\mathrm{Dmim}][\mathrm{Cl}]$} & [18] \\
\hline 1-(Ethoxycarbonyl)methyl-3-methylimidazolium bromide & {$[$ Ecmmim $][\mathrm{Br}]$} & [19] \\
\hline 1-Ethyl-3-methylimidazolium bromide & {$[\mathrm{Emim}][\mathrm{Br}]$} & [20] \\
\hline 1-Ethyl-3-methylimidazolium chloride & {$[\mathrm{Emim}][\mathrm{Cl}]$} & [21] \\
\hline 1-Hexadecyl-3-methylimidazolium bromide & {$[\mathrm{Hdmim}][\mathrm{Br}]$} & [22] \\
\hline 1-Hexadecyl-3-methylimidazolium chloride & {$[\mathrm{Hdmim}][\mathrm{Cl}]$} & {$[10,23]$} \\
\hline 1-Hexyl-3-methylimidazolium bromide & {$[\mathrm{Hmim}][\mathrm{Br}]$} & [20] \\
\hline 1-Hexyl-3-methylimidazolium chloride & {$[\mathrm{Hmim}][\mathrm{Cl}]$} & [10] \\
\hline 1-Methyl-3-carboxymethylimidazolium chloride & {$[\mathrm{Mcmim}][\mathrm{Cl}]$} & {$[24]$} \\
\hline 1-Methyl-3-dodecylimidazolium bromide & [Mddim][Br] & {$[25,26]$} \\
\hline 1-Methyl-3-octadecylimidazolium bromide & [Modim] $[\mathrm{Br}]$ & {$[25]$} \\
\hline 1-Methyl-3-octylimidazolium bromide & [Moim][Br] & [25] \\
\hline 1-Methyl-3-octylimidazolium chloride & [Moim] $[\mathrm{Cl}]$ & {$[4]$} \\
\hline 1-Methylimidazolium chloride & {$[\mathrm{Mim}][\mathrm{Cl}]$} & [27] \\
\hline 1-Allyl-3-methylimidazolium hexafluorophosphate & {$[$ Amim $]\left[\mathrm{PF}_{6}\right]$} & [28] \\
\hline 1-Butyl-3-methylimidazolium hexafluorophosphate & {$[\mathrm{Bmim}]\left[\mathrm{PF}_{6}\right]$} & [28-34] \\
\hline 1-Hexadecyl-3-methylimidazolium hexafluorophosphate & {$[\mathrm{Hdmim}]\left[\mathrm{PF}_{6}\right]$} & [22] \\
\hline 1-Hexyl-3-methylimidazolium hexafluorophosphate & {$[\mathrm{Hmim}]\left[\mathrm{PF}_{6}\right]$} & {$[34]$} \\
\hline $\begin{array}{l}\text { 1-(3-Butoxy-2-hydroxy-propyl)-3-methylimidazolium } \\
\text { tetrafluoroborate }\end{array}$ & {$[\mathrm{Bhpmim}]\left[\mathrm{BF}_{4}\right]$} & [35] \\
\hline 1-Butyl-3-methylimidazolium tetrafluoroborate & {$[\mathrm{Bmim}]\left[\mathrm{BF}_{4}\right]$} & [36-39] \\
\hline 1-Ethyl-3-methylimidazolium tetrafluoroborate & {$[\mathrm{Emim}]\left[\mathrm{BF}_{4}\right]$} & {$[28,40]$} \\
\hline 1-Hexyl-3-methylimidazolium tetrafluoroborate & {$[\mathrm{Hmim}]\left[\mathrm{BF}_{4}\right]$} & {$[36]$} \\
\hline 1-Vinyl-3-ethylimidazolium tetrafluoroborate & {$[$ Veim $]\left[\mathrm{BF}_{4}\right]$} & {$[41]$} \\
\hline $\begin{array}{l}\text { 1-Butyl-3-methylimidazolium } \\
\text { bis(trifluoromethylsulfonyl)imide }\end{array}$ & {$[\mathrm{Bmim}]\left[\mathrm{NTf}_{2}\right]$} & [42-51] \\
\hline $\begin{array}{l}\text { 1-Carboxyethyl-3-methylimidazolium } \\
\text { bis(trifluoromethylsulfonyl)imide }\end{array}$ & {$[$ Cemim $]\left[\mathrm{NTf}_{2}\right]$} & [52] \\
\hline $\begin{array}{l}\text { 1-Ethyl-2,3-dimethylimidazolium } \\
\text { bis(trifluoromethylsulfonyl)imide }\end{array}$ & {$[\mathrm{Edmim}]\left[\mathrm{NTf}_{2}\right]$} & [53] \\
\hline $\begin{array}{l}\text { 1-Ethyl-3-methylimidazolium } \\
\text { bis(trifluoromethylsulfonyl)imide }\end{array}$ & {$[$ Emim $]\left[\mathrm{NTf}_{2}\right]$} & {$[54,55]$} \\
\hline $\begin{array}{l}\text { 1-Methyl-3-dodecylimidazolium } \\
\text { bis(trifluoromethylsulfonyl)imide }\end{array}$ & {$[\mathrm{Mddim}]\left[\mathrm{NTf}_{2}\right]$} & [26] \\
\hline
\end{tabular}

Meanwhile, Table 2 exhibits examples of polymer matrices and nanofillers used for fabrication of polymer nanocomposites. Thermoplastics, such as EVM [40], ImPEEK [8], Pebax [9], PEI [32], PEO [38], PI [39], PLLA [19], PMMA [26,34], PVA [7], and PVDF [22,28,54] have been used as polymer matrices for fabricating polymer nanocomposites. On the other hand, elastomers, for example, BIIR [29], AEM [4], EPDM [17], NR [5], NRL [20,51], CR [42-44,46-50], PDMS [55], and SBR [11-16,18,45,53], have frequently been used as polymer matrices. In addition, polymer nanocomposites can be fabricated by using thermosets 
like DGEAC [35], DGEBA [33,37], and PUF [21,31]. Furthermore, PEDOT [36] and PTh [25] are conductive polymers that can also be used for fabrication of polymer nanocomposites. Additionally, nanomaterials, such as MWCNTs [4,32,34,40,55], MWCNT-COOH [8,30,52], GO [6,27], GN [19,39], GNP [26], nano-SiO 2 [5,17], nano- $\mathrm{TiO}_{2}$ [24], ZnO NPs [38], CB NPs [41], and MMT [10,23] have been used as nanofillers for polymer nanocomposites because of their high aspect ratio, large surface area, high stiffness, and low density [56].

Table 2. Examples of polymer matrices and nanofillers used for fabrication of polymer nanocomposites.

\begin{tabular}{|c|c|c|c|}
\hline Polymer Matrix & Abbreviation & Nanofiller & Abbreviation \\
\hline Ethylene-vinyl acetate & EVM & Multi-walled carbon nanotubes & MWCNTs \\
\hline Imidazolium-based poly(ether ether ketone) & ImPEEK & $\begin{array}{c}\text { Carboxylated multi-walled carbon } \\
\text { nanotubes }\end{array}$ & MWCNT-COOH \\
\hline Polyether block amide & Pebax & Graphene oxide & GO \\
\hline Polyetherimide & PEI & Graphene nanosheets & GN \\
\hline Poly(ethylene oxide) & PEO & Graphene nanoplatelets & GNP \\
\hline Polyimide & PI & Nanosilica & nano-SiO 2 \\
\hline Poly(L-lactic acid) & PLLA & Titanium dioxide nanoparticles & nano- $\mathrm{TiO}_{2}$ \\
\hline Poly(methyl methacrylate) & PMMA & Zinc oxide nanoparticles & $\mathrm{ZnO} N P s$ \\
\hline Polyvinyl alcohol & PVA & Carbon black nanoparticles & CB NPs \\
\hline Poly(vinylidene fluoride) & PVDF & Montmorillonite & MMT \\
\hline Bromobutyl rubber & BIIR & & \\
\hline Ethylene acrylic elastomer & AEM & & \\
\hline Ethylene-propylene-diene & EPDM & & \\
\hline Natural rubber & NR & & \\
\hline Natural rubber latex & NRL & & \\
\hline Polychloroprene rubber & CR & & \\
\hline Polydimethylsiloxane & PDMS & & \\
\hline Styrene butadiene rubber & SBR & & \\
\hline Diglycidyl ester of aliphatic cyclo & DGEAC & & \\
\hline Diglycidyl ether of bisphenol A & DGEBA & & \\
\hline Polyurethane foam & PUF & & \\
\hline Poly(3,4-ethylene dioxythiophene) & PEDOT & & \\
\hline Polythiophene & PTh & & \\
\hline
\end{tabular}

In the past ten years, numerous nanofiller modification processes have been proposed with the aim of improving the physicochemical properties of polymer nanocomposites. The employment of ionic liquids as modifiers could give a benefit due to their unique chemical structure, which possesses both bulky cations and anions that are poorly coordinated. These ions are capable of interacting with organic polymers and inorganic nanofillers. The presence of intermolecular interactions could have a modification effect on polymer nanocomposites and subsequently enhance the interface linkage between the polymer matrix and the nanofiller. As far as the authors know, no succinct review has been created focusing on the study of processes and thermo-mechanico-chemical properties of ionic liquid-modified nanofiller/polymer nanocomposites. That is the intention of creating the classified review presented in this paper. Moreover, this succinct review is general, and even though not specific, it is nevertheless relevant to other related studies.

\section{Types of Imidazolium-Based Ionic Liquids}

\subsection{Alkylimidazolium Halide Ionic Liquids}

Imidazolium-based ionic liquids with halide counter anions (denoted as alkylimidazolium halide ionic liquids) can be synthesized via two reaction processes, specifically protonation and alkylation reactions [57]. Alkylimidazolium halide ionic liquids that are synthesized via protonation reaction can be prepared by reacting $N$-alkylimidazole with hydrohalic acid in a polar solvent, such as ethanol, at slightly above room temperature while stirring [27]. Meanwhile, the alkylation reaction can be conducted by reacting $N$ alkylimidazole with alkyl halide under reflux conditions at an elevated temperature while 
stirring [58]. Figure 1 shows the schematic of the protonation reaction of $\mathrm{N}$-alkylimidazole with hydrohalic acid to prepare alkylimidazolium halide ionic liquid. Hydrohalic acids, such as hydrochloric acid and hydrobromic acid, are frequently used for protonation reaction, since they have the capacity to protonate (or hydronate) the nitrogen atom situated at the third position of the imidazole ring. Figure 2 indicates the schematic of the alkylation reaction of $\mathrm{N}$-alkylimidazole with alkyl halide to prepare alkylimidazolium halide ionic liquid. Alkyl halides, such as allyl-, butyl-, decyl-, and ethyl halides, are commonly used for alkylation reactions in the production of ionic liquids with different alkyl chain lengths. Additionally, these ionic liquids can be applied as precursors in the preparation of other ionic liquids [22,26].

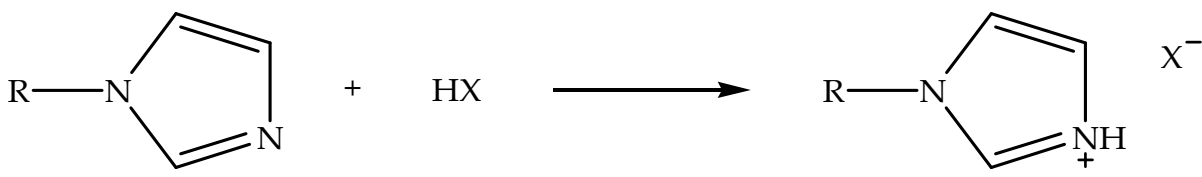

$$
\mathrm{R}=\mathrm{Alkyl} \quad \mathrm{X}=\mathrm{Cl}, \mathrm{Br}
$$

Figure 1. Schematic of the protonation reaction of $\mathrm{N}$-alkylimidazole with hydrohalic acid to prepare alkylimidazolium halide ionic liquid.

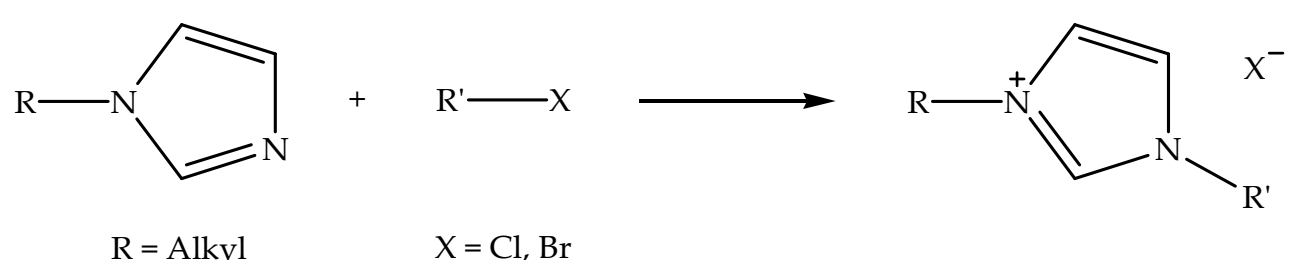

Figure 2. Schematic of the alkylation reaction of $N$-alkylimidazole with alkyl halide to prepare alkylimidazolium halide ionic liquid.

Additionally, alkylimidazolium halide ionic liquids are generally used for dissolution of biopolymers as ionic liquids with carboxylate anions, such as alkylimidazolium acetate and alkylimidazolium propionate [58]. Table 3 demonstrates the types of imidazoliumbased ionic liquids, nanofillers, and modification processes of nanofillers. It can be observed that different types of nanofillers, for example, MWCNTs, nano-SiO ${ }_{2}, \mathrm{GO}, \mathrm{MWCNT}-\mathrm{COOH}$, MMT, GN, and GNP, can be modified with alkylimidazolium halide ionic liquids using different modification processes. The most common processes are ultrasonication and sonication, with both processes having almost the same concept, but different apparatuses, e.g., the ultrasonication process can be done using an ultrasonic bath $[4,25,54]$. In contrast, the sonication process can be performed by using an ultrasonic homogenizer probe sonicator $[7,26,55]$. Moreover, the processes do not require high temperatures and a long time, like refluxation [8]. On top of that, modification of nanofillers with alkylimidazolium halide ionic liquids can also be accomplished using low-cost processes, such as stirring and grinding. However, the modification of $\mathrm{GO}$ via stirring requires a higher temperature than MMT [9]. 
Table 3. Types of imidazolium-based ionic liquids, nanofillers, and modification processes of nanofillers.

\begin{tabular}{|c|c|c|c|c|c|}
\hline Ionic Liquid & Nanofiller & $\begin{array}{l}\text { Modification } \\
\text { Process }\end{array}$ & $\begin{array}{c}\text { Modification } \\
\text { Temperature } \\
\left({ }^{\circ} \mathrm{C}\right)\end{array}$ & $\begin{array}{l}\text { Time } \\
\text { (Hour) }\end{array}$ & References \\
\hline$[\mathrm{Amim}][\mathrm{Cl}]$ & MWCNTs & Ultrasonication & $\mathrm{R}$ & $\mathrm{U}$ & {$[4]$} \\
\hline$[\mathrm{Amim}][\mathrm{Cl}]$ & nano-SiO 2 & Ultrasonication & $\mathrm{R}$ & 1 & [5] \\
\hline$[\mathrm{Amim}][\mathrm{Cl}]$ & $\mathrm{GO}$ & Ultrasonication & $\mathrm{R}$ & 0.5 & [6] \\
\hline [Apmbim][Br] & MWCNT-COOH & Refluxation & 60 & 24 & [8] \\
\hline [Apmim][Br] & GO & Stirring & 80 & 24 & [9] \\
\hline$[\mathrm{Bmim}][\mathrm{Cl}]$ & MMT & Stirring & $\mathrm{R}$ & $\mathrm{U}$ & [10] \\
\hline$[$ Bzmim] $[\mathrm{Cl}]$ & MWCNTs & Sonication & $\mathrm{R}$ & 0.5 & [11] \\
\hline$[\mathrm{Dmim}][\mathrm{Br}]$ & nano- $\mathrm{SiO}_{2}$ & Ultrasonication & $\mathrm{R}$ & 0.25 & [17] \\
\hline$[\mathrm{Dmim}][\mathrm{Cl}]$ & MWCNTs & Sonication & $\mathrm{R}$ & 2 & [18] \\
\hline$[$ Ecmmim] $[\mathrm{Br}]$ & GN & Sonication & $\mathrm{R}$ & 4 & [19] \\
\hline$[\mathrm{Emim}][\mathrm{Br}]$ & MWCNTs & Ultrasonication & $\mathrm{R}$ & 2 & [20] \\
\hline$[\mathrm{Hdmim}][\mathrm{Br}]$ & MWCNTs & Sonication & $\mathrm{R}$ & 0.5 & [22] \\
\hline$[\mathrm{Hdmim}][\mathrm{Cl}]$ & MMT & Stirring & $\mathrm{R}$ & 24 & [23] \\
\hline [Mddim][Br] & GNP & Grinding & $\mathrm{R}$ & 0.17 & [26] \\
\hline$[\mathrm{Mim}][\mathrm{Cl}]$ & GO & Stirring & 35 & 12 & [27] \\
\hline$[$ Amim $]\left[\mathrm{PF}_{6}\right]$ & MWCNTs & Grinding & $\mathrm{R}$ & 8 & [28] \\
\hline$[\mathrm{Bmim}]\left[\mathrm{PF}_{6}\right]$ & GO & Ultrasonication & $\mathrm{R}$ & 0.5 & [29] \\
\hline$[\mathrm{Bmim}]\left[\mathrm{PF}_{6}\right]$ & MWCNT-COOH & Grinding & $\mathrm{R}$ & 0.25 & [30] \\
\hline$[\mathrm{Bmim}]\left[\mathrm{PF}_{6}\right]$ & nano- $\mathrm{SiO}_{2}$ & Stirring & $\mathrm{R}$ & $\mathrm{U}$ & [31] \\
\hline$[\mathrm{Bmim}]\left[\mathrm{PF}_{6}\right]$ & MWCNTs & Grinding & $\mathrm{R}$ & 0.5 & [32] \\
\hline$[\mathrm{Bmim}]\left[\mathrm{PF}_{6}\right]$ & MWCNTs & Ultrasonication & $\mathrm{R}$ & 1 & [33] \\
\hline$[\mathrm{Hdmim}]\left[\mathrm{PF}_{6}\right]$ & MWCNTs & Sonication & $\mathrm{R}$ & 0.5 & [22] \\
\hline$[\mathrm{Hmim}]\left[\mathrm{PF}_{6}\right]$ & MWCNTs & Milling & $\mathrm{R}$ & 0.17 & [34] \\
\hline$[$ Bhpmim $]\left[\mathrm{BF}_{4}\right]$ & GO & Irradiation & 20 & 0.02 & [35] \\
\hline$[\mathrm{Bmim}]\left[\mathrm{BF}_{4}\right]$ & MWCNTs & Grinding & $\mathrm{R}$ & 0.3 & [37] \\
\hline$[\mathrm{Bmim}]\left[\mathrm{BF}_{4}\right]$ & $\mathrm{ZnO} N P s$ & Sonication & $\mathrm{R}$ & $\mathrm{U}$ & [38] \\
\hline$[\mathrm{Bmim}]\left[\mathrm{BF}_{4}\right]$ & GN & Stirring & 80 & 24 & [39] \\
\hline$[\mathrm{Emim}]\left[\mathrm{BF}_{4}\right]$ & MWCNTs & Grinding & $\mathrm{R}$ & 8 & [28] \\
\hline$[\mathrm{Emim}]\left[\mathrm{BF}_{4}\right]$ & MWCNTs & Grinding & $\mathrm{R}$ & 0.3 & {$[40]$} \\
\hline$[\mathrm{Hmim}]\left[\mathrm{BF}_{4}\right]$ & GO & Stirring & $\mathrm{R}$ & $\mathrm{U}$ & [36] \\
\hline$[$ Veim $]\left[\mathrm{BF}_{4}\right]$ & CB NPs & Grinding & $\mathrm{R}$ & $\mathrm{U}$ & [41] \\
\hline$[\mathrm{Bmim}]\left[\mathrm{NTf}_{2}\right]$ & MWCNTs & Grinding & $\mathrm{R}$ & $\mathrm{U}$ & [42] \\
\hline$[\mathrm{Bmim}]\left[\mathrm{NTf}_{2}\right]$ & MWCNTs & Sonication & $\mathrm{R}$ & 0.3 & [51] \\
\hline$\left[\right.$ Cemim] $\left[\mathrm{NTf}_{2}\right]$ & MWCNT-COOH & Ultrasonication & $\mathrm{R}$ & 0.25 & [52] \\
\hline$[\mathrm{Edmim}]\left[\mathrm{NTf}_{2}\right]$ & MWCNTs & Sonication & $\mathrm{R}$ & 0.5 & [53] \\
\hline$[\mathrm{Emim}]\left[\mathrm{NTf}_{2}\right]$ & MWCNTs & Ultrasonication & $\mathrm{R}$ & 0.5 & [54] \\
\hline$[\mathrm{Emim}]\left[\mathrm{NTf}_{2}\right]$ & MWCNTs & Grinding & $\mathrm{R}$ & $\mathrm{U}$ & {$[55]$} \\
\hline$\left[\right.$ Mddim] $\left[\mathrm{NTf}_{2}\right]$ & GNP & Grinding & $\mathrm{R}$ & 0.17 & [26] \\
\hline
\end{tabular}

$\mathrm{R}=$ room, and $\mathrm{U}=$ unspecified.

\subsection{Alkylimidazolium Hexafluorophosphate Ionic Liquids}

Alkylimidazolium hexafluorophosphate ionic liquids can be synthesized through metathesis reaction by using alkylimidazolium halide ionic liquids as precursors [59]. The reaction process can be carried out by exchanging halide anion with a hexafluorophosphate anion by using a metal hexafluorophosphate salt. The ion exchange is usually conducted in a polar solvent, such as ethanol, at room temperature while stirring [58]. Figure 3 shows the schematic of the metathesis reaction of alkylimidazolium chloride with potassium hexafluorophosphate to prepare alkylimidazolium hexafluorophosphate ionic liquid. The metathesis reaction is a general process for exchanging counter anions. When the reaction is carried out in ethanol, the potassium chloride salt precipitates from the reaction solvent, since it is insoluble in ethanol, and the alkylimidazolium hexafluorophosphate ionic liquid remains in the solution. Moreover, the metathesis reaction is often applied for the production of hydrophobic and low-temperature ionic liquids, for instance, 1-butyl3-methylimidazolium- and 1-hexyl-3-methylimidazolium hexafluorophosphate [33,34]. 
Nevertheless, the physicochemical properties of the ionic liquids are different from the ionic liquids prepared via alkylation reaction, as a result of alkylimidazolium hexafluorophosphate possessing large-sized anions.

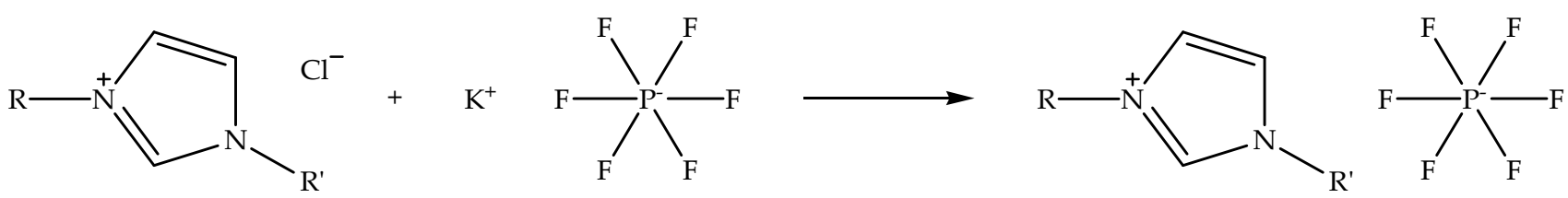

Figure 3. Schematic of the metathesis reaction of alkylimidazolium chloride with potassium hexafluorophosphate to prepare alkylimidazolium hexafluorophosphate ionic liquid.

Additionally, alkylimidazolium hexafluorophosphate ionic liquids can be applied in the chemical demulsification process. A previous review revealed that the ionic liquids could effectively demulsify emulsions compared to alkylimidazolium halide ionic liquids [60]. It can be seen in Table 3 that the nanofillers MWCNTs and MWCNT-COOH are frequently modified using alkylimidazolium hexafluorophosphate ionic liquids, and the grinding process is regularly performed to modify them [28,30,32]. Other processes, such as ultrasonication, sonication, and milling, can also be used for the modification of MWCNTs at room temperature $[22,33,34]$. The processes induce the ionic liquids to be coated on the surface of the MWCNTs, forming bucky gels. Moreover, the hydrophobic nature of alkylimidazolium hexafluorophosphate ionic liquids makes them appropriate for application as modifiers for hydrophobic nanofillers, such as MWCNTs, GO, and nano-SiO 2 [8,31]. This property can also form interactions between the nanofillers and hydrophobic polymer matrices by acting as an interface linker of polymer nanocomposites in order to tune their properties.

\subsection{Alkylimidazolium Tetrafluoroborate Ionic Liquids}

Alkylimidazolium tetrafluoroborate ionic liquids can not only be synthesized via metathesis reaction, but also through acid-base reaction by neutralizing alkylimidazolium hydroxide with fluoroboric acids such as tetrafluoroboric acid. Figure 4 shows the schematic of the neutralization of alkylimidazolium hydroxide with tetrafluoroboric acid to prepare alkylimidazolium tetrafluoroborate ionic liquid. The reaction is typically carried out in a polar solvent like ethanol while stirring at room temperature [58]. Unlike the alkylimidazolium hexafluorophosphate ionic liquids, alkylimidazolium tetrafluoroborate can present two different properties, specifically hydrophilic and hydrophobic properties. The presence of both properties is influenced by the length of the alkylimidazolium chain; for example, 1-ethyl-3-methylimidazolium tetrafluoroborate is hydrophilic in nature, but 1-hexyl-3methylimidazolium tetrafluoroborate possesses the hydrophobic property. In addition, the melting point of the ionic liquids is also affected by their alkyl chain length, whereby the longer alkylimidazolium chain ionic liquids have a higher melting point, and the shorter alkylimidazolium chain ionic liquids exhibit the opposite characteristic. Therefore, the hydrophobicity and melting point of alkylimidazolium tetrafluoroborate ionic liquids can be tweaked by controlling the length of their alkyl chain.

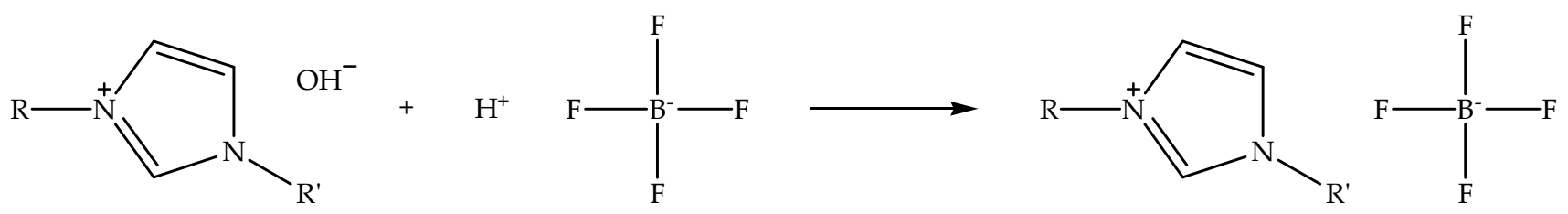

Figure 4. Schematic of the neutralization of alkylimidazolium hydroxide with tetrafluoroboric acid to prepare alkylimidazolium tetrafluoroborate ionic liquid.

Furthermore, alkylimidazolium tetrafluoroborate ionic liquids are typically exploited as plasticizing agents for synthetic biodegradable polymers [19]. In Table 3, it can be 
observed that the ionic liquids are able to modify various types of nanofillers, including GO, MWCNTs, ZnO NPs, GN, and CB NPs. The grinding process is commonly applied for the modification of nanofillers, as this does not consume solvent [28,37], as is required in sonication and stirring processes $[38,39]$. It can also be seen that the irradiation process by means of microwaves is the fastest process for modifying GO at $20^{\circ} \mathrm{C}$ [35]. Nevertheless, the modification of GN through the stirring process is a long process in comparison to the other processes, requiring $24 \mathrm{~h}$ at $80^{\circ} \mathrm{C}$ [39]. The processes for modifying different types of nanofillers using ionic liquids are generally optimized to improve the dispersion of nanofillers in the polymer matrices and enhancing the interface compatibility between them. The improved dispersion and compatibility of nanofillers results in high-performance polymer nanocomposites.

\subsection{Alkylimidazolium Bistriflimide Ionic Liquids}

Alkylimidazolium bis(trifluoromethylsulfonyl)imide ionic liquids (denoted as alkylimidazolium bistriflimide ionic liquids) can also be synthesized through metathesis reaction by exchanging halide anion of alkylimidazolium halide with a bistriflimide anion by using a metal bis(trifluoromethylsulfonyl)imide salt. The exchange process is generally performed in an aqueous solvent, such as distilled water, at an elevated temperature under nitrogen atmosphere [26]. Figure 5 displays the schematic of the metathesis reaction of alkylimidazolium bromide with lithium bis(trifluoromethylsulfonyl)imide to prepare alkylimidazolium bistriflimide ionic liquid. When the reaction is conducted in distilled water, the alkylimidazolium bistriflimide liquid separates from the aqueous solution, since it possesses the hydrophobic property, and the unreacted reactants remain in solution. Unlike the alkylimidazolium tetrafluoroborate ionic liquids, alkylimidazolium bistriflimide only exists as hydrophobic ionic liquids with a wide range of structures [17]. In addition, the ionic liquids are more air- and water-stable than alkylimidazolium halide ionic liquids. Additionally, the bistriflimide anion is not easily decomposed in the presence of water, as compared to tetrafluoroborate and hexafluorophosphate anions. Moreover, alkylimidazolium bistriflimide ionic liquids have a low melting point and are less viscous [48].<smiles>[Y]n1cc[n+]([Y])c1</smiles>

Figure 5. Schematic of the metathesis reaction of alkylimidazolium bromide with lithium bis(trifluoromethylsulfonyl)imide to prepare alkylimidazolium bistriflimide ionic liquid.

Furthermore, alkylimidazolium bistriflimide ionic liquids can be used as a compatibilizer for polymer blends. The preceding study determined that the ionic liquids were able to more efficiently compatibilize bioplastic/biopolymer blends in comparison to the alkylimidazolium halide ionic liquids [1]. It can be observed in Table 3 that the carbonbased nanofillers, such as MWCNTs, MWCNT-COOH, and GNP, are typically modified using alkylimidazolium bistriflimide ionic liquids. This is due to the ionic liquids having the capacity to interact with the surface of the carbon materials via cation- $\pi, \pi-\pi$, or van der Waals interactions $[26,51,54]$. On top of that, the modification process can be done either through grinding, sonication, or ultrasonication processes in solvent or solvent-free mediums $[42,52,53]$. Additionally, the processes are usually carried out at room temperature in less than an hour. Hence, the modification of nanofillers using alkylimidazolium bistriflimide ionic liquids possesses significant advantages, such as low materials depletion, simple modification process, and low energy consumption. 


\section{Types of Ionic Liquid-Modified Nanofiller/Polymer Nanocomposites}

\subsection{Ionic Liquid-Nanofiller/Thermoplastic Nanocomposites}

Thermoplastics are widely used as polymer matrices in the fabrication of polymer nanocomposites. This is due to the fact that they can be processed either in the molten state or in the solution state. Table 4 displays the types of polymer matrices, nanofillers, ionic liquids, and fabrication processes of polymer nanocomposites. It can be observed that PVDF thermoplastics are more often incorporated with ionic liquid-modified nanofillers than other thermoplastics. This can be attributed to the fact that ionic liquid-nanofiller/PVDF nanocomposites can potentially be applied in the production of dielectric [41], energy storage [23], piezoresistive [30], and hybrid membrane [24] materials. The mixing process for PVDF with ionic liquid-modified nanofillers can be carried out through melt blending at $190{ }^{\circ} \mathrm{C}[23,41]$ and solution blending in different solvents $[10,22,24]$. Meanwhile, other thermoplastics, such as EVM, ImPEEK, Pebax, PEI, PEO, PI, PLLA, PMMA, and PVA, can also be mixed with ionic liquid-modified nanofillers via the same processes at different temperatures or with different solvents. In addition, sonication or ultrasonication processes can also be applied during solution blending $[7,9,19,26,32]$. The final process is practically important for shaping the polymer nanocomposites prior to thermo-mechanico-chemical characterization. The process can be done through hot pressing or compression molding and solution or solvent casting processes.

Table 4. Types of polymer matrices, nanofillers, ionic liquids, and fabrication processes of polymer nanocomposites.

\begin{tabular}{|c|c|c|c|c|c|}
\hline Polymer Matrix & Nanofiller & Ionic Liquid & Mixing Process & Final Process & References \\
\hline EVM & MWCNTs & {$[\mathrm{Emim}]\left[\mathrm{BF}_{4}\right]$} & Melt blending & Hot pressing & [40] \\
\hline ImPEEK & MWCNT-COOH & [Apmbim][Br] & Solution blending & Solution casting & [8] \\
\hline Pebax & $\mathrm{GO}$ & [Apmbim][Br] & Sonication & Solution casting & [9] \\
\hline PEI & MWCNTs & {$\left[\mathrm{Bmim}^{2}\right]\left[\mathrm{PF}_{6}\right]$} & Sonication & Solution casting & [32] \\
\hline PEO & $\mathrm{ZnO} N P s$ & {$[\mathrm{Bmim}]\left[\mathrm{BF}_{4}\right]$} & Solution blending & Solution casting & [38] \\
\hline PI & GN & {$[\mathrm{Bmim}]\left[\mathrm{BF}_{4}\right]$} & Solution blending & Solution casting & [39] \\
\hline PLLA & GN & {$[$ Ecmmim] $[\mathrm{Br}]$} & Ultrasonication & Hot pressing & [19] \\
\hline PMMA & GNP & {$[\mathrm{Mddim}]\left[\mathrm{NTf}_{2}\right]$} & Sonication & Compression molding & [26] \\
\hline PMMA & MWCNTs & {$[\mathrm{Hmim}]\left[\mathrm{PF}_{6}\right]$} & Melt blending & Compression molding & [34] \\
\hline PVA & GO & {$[\mathrm{Amim}][\mathrm{Cl}]$} & Sonication & Solvent casting & [7] \\
\hline PVDF & CB NPs & [Veim] $\left[\mathrm{BF}_{4}\right]$ & Melt blending & Hot pressing & [41] \\
\hline PVDF & MMT & {$[\mathrm{Hdmim}][\mathrm{Cl}]$} & Melt blending & Compression molding & [23] \\
\hline PVDF & MMT & {$[\mathrm{Hmim}][\mathrm{Cl}]$} & Solution blending & Solution casting & [10] \\
\hline PVDF & MWCNTs & {$[\mathrm{Hdmim}]\left[\mathrm{PF}_{6}\right]$} & Solution blending & Compression molding & [22] \\
\hline PVDF & MWCNT-COOH & {$[\mathrm{Bmim}]\left[\mathrm{PF}_{6}\right]$} & Melt blending & Compression molding & [30] \\
\hline PVDF & nano- $\mathrm{TiO}_{2}$ & {$[\mathrm{Mcmim}][\mathrm{Cl}]$} & Solution blending & Hot pressing & [24] \\
\hline AEM & MWCNTs & {$[\mathrm{Amim}][\mathrm{Cl}]$} & Hot mixing & Heat curing & {$[4]$} \\
\hline BIIR & GO & {$[\mathrm{Bmim}]\left[\mathrm{PF}_{6}\right]$} & Mill mixing & Heat curing & [29] \\
\hline CR & MWCNTs & {$[\mathrm{Bmim}]\left[\mathrm{NTf}_{2}\right]$} & Mill mixing & Heat curing & [42] \\
\hline CR & MWCNT-COOH & {$\left[\right.$ Cemim] $\left[\mathrm{NTf}_{2}\right]$} & Mill mixing & Heat curing & [52] \\
\hline EPDM & nano- $\mathrm{SiO}_{2}$ & {$[\mathrm{Dmim}][\mathrm{Br}]$} & Mill mixing & Heat curing & [17] \\
\hline NR & nano- $\mathrm{SiO}_{2}$ & {$[\mathrm{Amim}][\mathrm{Cl}]$} & Mill mixing & Heat curing & [5] \\
\hline NRL & MWCNTs & {$[\mathrm{Emim}][\mathrm{Br}]$} & Mill mixing & Heat curing & [20] \\
\hline PDMS & MWCNTs & {$[\mathrm{Emim}]\left[\mathrm{NTf}_{2}\right]$} & Speed mixing & Heat curing & [55] \\
\hline SBR & GO & {$[\mathrm{Amim}][\mathrm{Cl}]$} & Mill mixing & Heat curing & {$[6]$} \\
\hline SBR & MWCNTs & {$[$ Bzmim $][\mathrm{Cl}]$} & Mill mixing & Heat curing & [11] \\
\hline DGEAC & GO & {$[$ Bhpmim $]\left[\mathrm{BF}_{4}\right]$} & Solvent-free blending & Microwave curing & [35] \\
\hline DGEBA & MWCNTs & {$[\mathrm{Bmim}]\left[\mathrm{PF}_{6}\right]$} & Solution blending & Heat curing & [33] \\
\hline PUF & GO & {$[\mathrm{Mim}][\mathrm{Cl}]$} & Mill mixing & Compression molding & [27] \\
\hline PUF & nano-SiO 2 & {$[\mathrm{Bmim}]\left[\mathrm{PF}_{6}\right]$} & Solvent-free blending & Cast molding & [31] \\
\hline PUF & nano- $\mathrm{SiO}_{2}$ & {$[$ Emim $][\mathrm{Cl}]$} & Solvent-free blending & Cast molding & [21] \\
\hline
\end{tabular}




\subsection{Ionic Liquid-Nanofiller/Elastomer Nanocomposites}

Ionic liquid-modified nanofiller/polymer nanocomposites can also be fabricated by using elastomers as polymer matrices. Ionic liquid-nanofiller/elastomer nanocomposites are more environmentally friendly than conventional elastomer composites due to the cleaner processes involving the use of ionic liquids [20]. It can be seen in Table 4 that elastomers such as CR and SBR are commonly incorporated with ionic liquid-modified nanofillers. The nanocomposites made from the elastomers can potentially be used in elastic conductors [42], electrochemistry [52], automobile components [6], and electromagnetic interference shielding [11]. Meanwhile, the mixing process for elastomers and ionic liquidmodified nanofillers can be performed by means of mill mixing, hot mixing, and speed mixing processes $[4,16,55]$. On the other hand, the elastomers require curatives (curing agents) $[4,17,42,52]$ for crosslinking to occur in the nanocomposites. Elastomers that are admixed with nanofiller-ionic liquid can be mixed with curatives prior to the final process. The heat curing process is typically conducted at an elevated temperature under moderate compression with an optimal curing time.

\subsection{Ionic Liquid-Nanofiller/Thermoset Nanocomposites}

Thermosets can also be used as polymer matrices for the fabrication of polymer nanocomposites. However, only a limited number of ionic liquid-nanofiller/thermoset nanocomposites have been found. In Table 4, it can be observed that the PUF thermoset has more frequently been incorporated with ionic liquid-modified nanofillers than other thermosets. This is probably due to the thermoset being able to be applied for the production of polymer nanocomposite foams with controlled porosity [27], improved physicomechanical properties [31], and enhanced flame retardancy [21]. The mixing process between the PUF and ionic liquid-modified nanofillers can be accomplished via solvent-free blending [21,31] and mill mixing [27] at room temperature. Meanwhile, other thermosets, such as DGEAC and DGEBA, can be mixed with ionic liquid-modified nanofillers as well through solventfree blending or solution blending [33,35], followed by the addition of curing agents. The final process is significant for the crosslinking reaction of the polymer nanocomposites prior to physicochemical characterization. The process can be completed via microwave curing, heat curing, compression molding, and cast molding, either at room temperature or at an elevated temperature.

\section{Effect of Imidazolium-Based Ionic Liquids on the Thermo-Mechanico-Chemical Properties}

\subsection{Effect of Alkylimidazolium Halide Ionic Liquids}

Table 5 shows the thermo-mechanico-chemical properties of imidazolium-based ionic liquid-modified nanofiller/polymer nanocomposites. Nano-SiO${ }_{2}$ modified with [Amim][Cl] ionic liquid has been employed for the fabrication of [Amim][Cl]-modified nano- $\mathrm{SiO}_{2} / \mathrm{NR}$ nanocomposites [5]. The thermal, mechanical, and chemical properties of the nanocomposites and their components were characterized by means of differential scanning calorimeter, universal testing machine, and FTIR spectrometer. The thermal properties, such as the glass transition temperature, of the [Amim][Cl]-nano- $\mathrm{SiO}_{2}$ increased by up to $14 \%$ in comparison to the pristine [Amim][Cl]. This was due to the motion of [Amim][Cl] being restricted by the strong interaction between the $[\mathrm{Amim}][\mathrm{Cl}]$ and nano- $\mathrm{SiO}_{2}$. On the other hand, the mechanical properties, such as the tensile strength, tensile modulus, and elongation at break, of the modified nano- $\mathrm{SiO}_{2} / \mathrm{NR}$ nanocomposites increased by up to $102 \%, 28 \%$, and $24 \%$, respectively, compared to the unmodified nano- $\mathrm{SiO}_{2} / \mathrm{NR}$ nanocomposite. This was caused by the combinatory effects giving the homogenous dispersion of $[\mathrm{Amim}][\mathrm{Cl}]-$ nano- $\mathrm{SiO}_{2}$ and increasing the interactions between the nano- $\mathrm{SiO}_{2}$ and [Amim][Cl]. Additionally, the chemical properties, such as the absorption bands of the $\mathrm{C}-\mathrm{H}$ stretching vibrations, of the $[\mathrm{Amim}][\mathrm{Cl}]-$ nano- $\mathrm{SiO}_{2}$ shifted to higher wavenumber regions in comparison to the $\mathrm{C}-\mathrm{H}$ stretching vibrations of the pristine [Amim][Cl]. This indicated that the detachment of chloride anions from the $\mathrm{C}-\mathrm{H} \cdots \mathrm{Cl}^{-}$occurred because of 
the formation of the hydrogen bonding between the chloride anions and hydroxyl groups on the surface of nano- $\mathrm{SiO}_{2}$ [5]. Furthermore, interaction between the modified nano-SiO${ }_{2}$ and NR matrix was formed as well. Therefore, it can be deduced that the modification of nano- $\mathrm{SiO}_{2}$ with $[\mathrm{Amim}][\mathrm{Cl}]$ ionic liquid provides NR nanocomposites with high tensile strength and modulus properties, as well as good interaction.

Table 5. Thermo-mechanico-chemical properties of imidazolium-based ionic liquid-modified nanofiller/polymer nanocomposites.

\begin{tabular}{|c|c|c|c|c|c|c|c|c|c|c|}
\hline \multirow{2}{*}{ Ionic Liquid } & \multirow{2}{*}{$\begin{array}{c}\text { Polymer } \\
\text { Nanocomposite }\end{array}$} & \multicolumn{8}{|c|}{ Thermo-Mechanico-Chemical Properties * } & \multirow[t]{2}{*}{ References } \\
\hline & & $T_{\mathrm{g}}$ & $T_{\mathrm{c}}$ & $T_{\mathrm{m}}$ & $T_{\mathrm{d}}$ & TS & TM & EB & $\mathrm{Ch}$ & \\
\hline$[\mathrm{Amim}][\mathrm{Cl}]$ & nano-SiO $2 / \mathrm{NR}$ & $\Delta$ & $\bigcirc$ & $\bigcirc$ & $\bigcirc$ & $\Delta$ & $\Delta$ & $\Delta$ & $\Delta$ & {$[5]$} \\
\hline$[\mathrm{Bmim}][\mathrm{Cl}]$ & $\mathrm{MMT} / \mathrm{PVDF}$ & $\overline{0}$ & $\Delta$ & $\bigcirc$ & $\Delta$ & $\bar{\Delta}$ & $\Delta$ & $\bar{\Delta}$ & $\Delta$ & [10] \\
\hline$[\mathrm{Bzmim}][\mathrm{Cl}]$ & MWCNT/SBR & $\nabla$ & $\overline{0}$ & $\bigcirc$ & $\overline{0}$ & $\bar{\Delta}$ & $\Delta$ & $\bar{\nabla}$ & $\Delta$ & [13] \\
\hline$[\mathrm{Bmim}]\left[\mathrm{PF}_{6}\right]$ & MWCNT/PEI & $\Delta$ & $\bigcirc$ & $\bigcirc$ & $\Delta$ & $\bar{\Delta}$ & $\bar{\Delta}$ & $\nabla$ & $\bar{\Delta}$ & [32] \\
\hline$[\mathrm{Bmim}]\left[\mathrm{PF}_{6}\right]$ & nano-SiO $2 / P U F$ & $\bar{\Delta}$ & $\bigcirc$ & $\bigcirc$ & $\bar{\Delta}$ & $\bar{\Delta}$ & $\overline{0}$ & $\nabla$ & $\bar{\Delta}$ & [31] \\
\hline$[\mathrm{Hdmim}]\left[\mathrm{PF}_{6}\right]$ & MWCNT/PVDF & $\overline{0}$ & $\Delta$ & $\Delta$ & $\overline{0}$ & $\bar{\nabla}$ & $\bigcirc$ & $\nabla$ & $\bar{\Delta}$ & [22] \\
\hline$\left[\right.$ Bhpmim] $\left[\mathrm{BF}_{4}\right]$ & GO/DGEAC & $\Delta$ & $\overline{0}$ & $\overline{0}$ & $\Delta$ & $\Delta$ & $\Delta$ & $\bigcirc$ & $\bar{\Delta}$ & [35] \\
\hline$[\mathrm{Bmim}]\left[\mathrm{BF}_{4}\right]$ & $\mathrm{GN} / \mathrm{PI}$ & $\bar{\Delta}$ & $\bigcirc$ & $\bigcirc$ & $\bar{\Delta}$ & $\bar{\Delta}$ & $\bar{\Delta}$ & $\nabla$ & $\bar{\Delta}$ & [39] \\
\hline$[$ Emim $]\left[\mathrm{BF}_{4}\right]$ & MWCNT/EVM & $\bar{\Delta}$ & $\bigcirc$ & $\Delta$ & $\bar{\square}$ & $\bar{\Delta}$ & $\overline{0}$ & $\Delta$ & $\bar{\Delta}$ & [40] \\
\hline$[\mathrm{Bmim}]\left[\mathrm{NTf}_{2}\right]$ & MWCNT/CR & $\bar{\Delta}$ & $\bigcirc$ & $\bar{O}$ & $\bar{\Delta}$ & 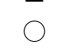 & $\Delta$ & $\bar{\Delta}$ & $\bar{\Delta}$ & [42] \\
\hline$[\mathrm{Bmim}]\left[\mathrm{NTf}_{2}\right]$ & MWCNT/NRL & $\bar{\Delta}$ & $\bigcirc$ & $\bigcirc$ & $\bar{\nabla}$ & $\nabla$ & $\bar{\Delta}$ & $\bar{\nabla}$ & $\bar{\Delta}$ & [51] \\
\hline$[\mathrm{Emim}]\left[\mathrm{NTf}_{2}\right]$ & MWCNT/PVDF & $\nabla$ & $\bigcirc$ & $\nabla$ & $\bigcirc$ & $\Delta$ & $\nabla$ & $\Delta$ & $\Delta$ & [54] \\
\hline
\end{tabular}

$T_{\mathrm{g}}=$ glass transition temperature, $T_{\mathrm{c}}=$ crystallization temperature, $T_{\mathrm{m}}=$ melting temperature, $T_{\mathrm{d}}=$ decomposition temperature, TS $=$ tensile strength, $\mathrm{TM}=$ tensile modulus, $\mathrm{EB}=$ elongation at break, $\mathrm{Ch}=$ chemical property. * The symbol ' $\boldsymbol{\Delta}$ ' corresponds to an increase in the properties, and ' $\boldsymbol{\nabla}$ ' to a decrease in the properties, while ' $\boldsymbol{\sigma}$ ' and ' $O$ ' describe unchanged and not available, respectively.

Meanwhile, MMT modified with [Bmim][Cl] ionic liquid has been employed for the fabrication of [Bmim][Cl]-modified MMT/PVDF nanocomposites [10]. The thermal, mechanical, and chemical properties of the nanocomposites and their components were characterized by using differential scanning calorimeter, thermogravimetric analyzer, universal testing machine, and FTIR spectrometer. The thermal properties, such as the crystallization temperature and maximum decomposition temperature, of the modified MMT/PVDF nanocomposites slightly increased by up to $2.9 \%$ and $0.6 \%$, respectively, compared to the unmodified MMT/PVDF nanocomposite. This was attributed to the presence of interaction between the $\mathrm{CH}_{2}-\mathrm{CF}_{2}$ of PVDF and the imidazolium ring of [Bmim][Cl]. In addition, the mechanical properties, such as the tensile strength, tensile modulus, and elongation at break, of the modified MMT / PVDF nanocomposites increased by up to $45 \%, 16 \%$, and $125 \%$, respectively, compared to the unmodified MMT/PVDF nanocomposite. This was caused by the formation of a structure with molecular orientation composed of an extended chain crystal and folded chain crystal in the modified MMT/PVDF nanocomposites. On top of that, the chemical properties, such as the absorption band of the $\mathrm{CF}_{2}-\mathrm{CH}_{2}$ stretching vibration, of the modified MMT/PVDF nanocomposite shifted to a lower wavenumber region in comparison to the $\mathrm{CF}_{2}-\mathrm{CH}_{2}$ stretching vibration of the neat PVDF. In contrast, the absorption band of the $\mathrm{CF}_{2}-\mathrm{CH}_{2}$ bending vibration of the modified MMT/PVDF nanocomposite shifted to a higher wavenumber region compared to the $\mathrm{CF}_{2}-\mathrm{CH}_{2}$ bending vibration of the neat PVDF. This was due to the formation of the $\beta$-phase due to the coulombic interaction between the imidazolium cations in the MMT interface and the negatively polarized $\mathrm{CF}_{2}$ groups in PVDF [10]. Thus, it can be inferred that the modification of MMT with [Bmim][Cl] ionic liquid gives PVDF nanocomposites high tensile strength and elongation properties, as well as good interaction.

Additionally, MWCNTs modified with [Bzmim][Cl] ionic liquid have been employed for the fabrication of [Bzmim][Cl]-modified MWCNT/SBR nanocomposites [13]. The thermal, mechanical, and chemical properties of the nanocomposites and their components were characterized by means of dynamic mechanical analyzer, universal testing machine, and Raman spectrometer. The thermal properties, such as the glass transition temperature, of the modified MWCNT/SBR nanocomposites decreased, which was attributed to the 
plasticizing effect of ionic liquid on the SBR matrix. This was also induced by the formation of the strong interaction between the modified MWCNT and SBR. On the other hand, the mechanical properties, such as the tensile strength and tensile modulus, of the modified MWCNT/SBR nanocomposites significantly increased by up to $317 \%$ and $348 \%$, respectively, compared to the neat SBR. This was due to the [Bzmim] $[\mathrm{Cl}]$ assisting the dispersion of MWCNTs, which enhanced stress transfer from the matrix to the nanofiller. Moreover, the good adhesion at the interfacial of MWCNTs/SBR was also able to improve the mechanical properties, due to the formation of the physical adsorption and the chemical bonding between the modified nanofiller and polymer matrix. Nevertheless, the elongation at break of the modified MWCNT/SBR nanocomposites decreased because of the existence of physical crosslinks in SBR nanocomposites, which acted as blocks for deformation. In addition, the chemical properties, such as the G band, of the modified MWCNT/SBR nanocomposite shifted to a lower wavenumber region in comparison to the $G$ band of the pristine MWCNTs. This was due to the realignment of [Bzmim][Cl]-MWCNTs themselves in the SBR matrix, which prompted an improved arrangement of MWCNTs in the nanocomposites [13]. Hence, it can be concluded that the modification of MWCNTs with [Bzmim][Cl] ionic liquid grants SBR nanocomposites high tensile strength and modulus properties, as well as good adhesion.

\subsection{Effect of Alkylimidazolium Hexafluorophosphate Ionic Liquids}

MWCNTs modified with $[\mathrm{Bmim}]\left[\mathrm{PF}_{6}\right]$ ionic liquid have been employed for the fabrication of [Bmim] $\left[\mathrm{PF}_{6}\right]$-modified MWCNT/PEI nanocomposites [32]. The thermal, mechanical, and chemical properties of the nanocomposites and their components were characterized by using differential scanning calorimeter, thermogravimetric analyzer, universal testing machine, and Raman spectrometer. The thermal properties, such as the glass transition temperature, of the modified MWCNT/PEI nanocomposites increased by up to $14 \%$ in comparison to the PEI containing ionic liquid (Table 5). This was caused by the restricting effect of MWCNTs as the movement of the PEI molecular chains is reduced. Additionally, the increment of the temperature was also due to the well-dispersed MWCNTs in the nanocomposites modified by [Bmim] $\left[\mathrm{PF}_{6}\right]$. Additionally, the initial decomposition temperature of the modified MWCNT/PEI nanocomposites increased by up to $33 \%$ compared to the PEI containing ionic liquid. This was attributed to the existence of strong interfacial interaction between the $\left[\mathrm{Bmim}^{-}\left[\mathrm{PF}_{6}\right]-\mathrm{MWCNT}\right.$ and PEI, which slowed down the decomposition rate of the nanocomposites. Moreover, the molecular chains of PEI were able to wrap the well-dispersed MWCNTs and provide restricted segments that resulted in high thermal stability of the nanocomposites. On top of that, the mechanical properties, such as the tensile strength and tensile modulus, of the modified MWCNT/PEI nanocomposites increased by up to $41 \%$ and $32 \%$, respectively, compared to the neat PEI. This was owing to the strong interfacial interactions between the modified MWCNT and PEI matrix, which gave the nanocomposites stiffer and stronger properties. However, the elongation at break of the modified MWCNT/PEI nanocomposites decreased because of the formation of the MWCNTs networks in the PEI matrix. Furthermore, the chemical properties, such as the $\mathrm{D}$ band, of the modified MWCNT shifted to a higher wavenumber region in comparison to the $\mathrm{D}$ band of the pristine MWCNTs. This was due to the adhesion of the $\left[\mathrm{Bmim}^{-}\left[\mathrm{PF}_{6}\right]\right.$ molecules via cation- $\pi$ or $\pi-\pi$ interactions on the MWCNT surface [32]. Therefore, it can be deduced that the modification of MWCNTs with $\left[\mathrm{Bmim}^{\mathrm{N}}\right]\left[\mathrm{PF}_{6}\right]$ ionic liquid provides PEI nanocomposites with high thermal stability and high tensile strength and modulus properties, as well as good interaction.

Meanwhile, nano- $\mathrm{SiO}_{2}$ modified with $[\mathrm{Bmim}]\left[\mathrm{PF}_{6}\right]$ ionic liquid has been employed for the fabrication of $[\mathrm{Bmim}]\left[\mathrm{PF}_{6}\right]$-modified nano-SiO $2 / \mathrm{PUF}$ nanocomposites [31]. The thermal, mechanical, and chemical properties of the nanocomposites and their components were characterized by means of dynamic mechanical analyzer, thermogravimetric analyzer, testing machine, and FTIR spectrometer. The thermal properties, such as the glass transition temperature, of the modified nano- $\mathrm{SiO}_{2} / \mathrm{PUF}$ nanocomposites increased by up to 
$20 \%$ in comparison to the unmodified nano-SiO ${ }_{2} / \mathrm{PUF}$ nanocomposite. This was due to an improvement in the rigidity of the nanocomposites, which was induced by high crosslink density with the incorporation of $[\mathrm{Bmim}]\left[\mathrm{PF}_{6}\right]-$ nano-SiO${ }_{2}$. In addition, the initial decomposition temperature of the modified nano-SiO $2 / \mathrm{PUF}$ nanocomposites increased by up to $10 \%$ compared to the unmodified nano- $-\mathrm{SiO}_{2} / \mathrm{PUF}$ nanocomposite. This was attributed to the good dispersion of the modified nano- $\mathrm{SiO}_{2}$ and homogeneous microstructure of the nanocomposites, which significantly enhanced the thermal stability of the nanocomposites. On the other hand, the mechanical properties, such as the flexural strength of the modified nano- $\mathrm{SiO}_{2} / \mathrm{PUF}$ nanocomposites, increased by up to $15 \%$ in comparison to the unmodified nano-SiO 2 /PUF nanocomposite. This was because of the compatibilizing effect of $[\mathrm{Bmim}]\left[\mathrm{PF}_{6}\right]$ on the nanocomposites. Nevertheless, the elongation at break of the modified nano- $\mathrm{SiO}_{2}$ /PUF nanocomposites decreased, which was caused by the presence of nano$\mathrm{SiO}_{2}$ aggregates that probably acted as defects for the PUF matrix, reducing the extension of the nanocomposites. Moreover, the chemical properties, such as the absorption band of the $\mathrm{C}=\mathrm{O}$ stretching vibration of the carbonyl groups of the modified nano-SiO $\mathrm{S}_{2} / \mathrm{PUF}$ nanocomposite shifted to a higher wavenumber region in comparison to the $\mathrm{C}=\mathrm{O}$ stretching vibration of the neat PUF. This was due to the hydrogen bonding between the $\mathrm{NH}$ and $\mathrm{C}=\mathrm{O}$ of the matrix disturbed by the incorporation of the modified nano- $\mathrm{SiO}_{2}$, which improved the interfacial adhesion between the PUF and nano- $\mathrm{SiO}_{2}$ [31]. Thus, it can be inferred that the modification of nano-SiO${ }_{2}$ with $\left[\mathrm{Bmim}_{[}\right]\left[\mathrm{PF}_{6}\right]$ ionic liquid gives PUF nanocomposites high thermal and tensile strength properties, as well as good adhesion.

Additionally, MWCNTs modified with $[\mathrm{Hdmim}]\left[\mathrm{PF}_{6}\right]$ ionic liquid have been employed for the fabrication of [Hdmim] $\left[\mathrm{PF}_{6}\right]$-modified MWCNT/PVDF nanocomposites [22]. The thermal, mechanical, and chemical properties of the nanocomposites and their components were characterized by using differential scanning calorimeter, universal testing machine, and FTIR spectrometer, respectively. The thermal properties, such as the crystallization temperature of the modified MWCNT/PVDF nanocomposites moderately increased by up to $4.3 \%$ in comparison to the unmodified MWCNT/PVDF nanocomposite. This was due to the efficiency of modified MWCNT to act as a nucleation agent for the PVDF compared to the pristine MWCNTs, which accelerated the crystallization of PVDF. In addition, the melting temperature of the modified MWCNT/PVDF nanocomposites moderately increased by up to $3.3 \%$ in comparison to the unmodified MWCNT/PVDF nanocomposite. This was attributed to the disruption of $[\mathrm{Hdmim}]\left[\mathrm{PF}_{6}\right]$, which complemented the effect of promoting on crystallization of PVDF. Nevertheless, the mechanical properties, such as the tensile strength and elongation at break of the modified MWCNT/PVDF nanocomposites slightly decreased possibly because of the presence of micro-stress, which required less force for deformation, and consequently reduced the strength and elongation. However, the elongation at break of the modified MWCNT/PVDF nanocomposites is significantly higher compared to neat PVDF, which indicated that the plasticizing effect of ionic liquid on the polymer matrix. On the other hand, the chemical properties, such as the absorption band of the $-\mathrm{CF}_{2}$ stretching vibration, of the modified MWCNT/PVDF nanocomposites shifted to a higher wavenumber region in comparison to the $-\mathrm{CF}_{2}$ stretching vibration of the unmodified MWCNT/PVDF nanocomposite. This was due to the role of [Hdmim] $\left[\mathrm{PF}_{6}\right]$, which acted as a linker for improving the compatibility between the MWCNTs surfaces and molecular chains of PVDF [22]. Hence, it can be concluded that the modification of MWCNTs with $[\mathrm{Hdmim}]\left[\mathrm{PF}_{6}\right]$ ionic liquid grants PVDF nanocomposites moderate crystallization and melting temperatures, as well as good compatibility.

\subsection{Effect of Alkylimidazolium Tetrafluoroborate Ionic Liquids}

GO modified with $[\mathrm{Bhpmim}]\left[\mathrm{BF}_{4}\right]$ ionic liquid has been employed for the fabrication of [Bhpmim] $\left[\mathrm{BF}_{4}\right]$-modified GO/DGEAC nanocomposites [35]. The thermal, mechanical, and chemical properties of the nanocomposites and their components were characterized by means of dynamic mechanical thermal analyzer, thermogravimetric analyzer, mechanical testing machine, and Raman spectrometer. The thermal properties, such as the glass 
transition temperature, of the modified GO/DGEAC nanocomposites slightly increased by up to $2.4 \%$ in comparison to the unmodified GO/DGEAC nanocomposite (Table 5). This was due to the introduction of $[\mathrm{Bhpmim}]\left[\mathrm{BF}_{4}\right]$ efficiently enhancing the interfacial bonding between the GO nanofiller and DGEAC matrix, which efficiently strengthened the nanocomposite system. In addition, the maximum decomposition temperature of the [Bhpmim] $\left[\mathrm{BF}_{4}\right]-\mathrm{GO}$ increased by approximately up to $10 \%$ compared to the pristine [Bhpmim] $\left[\mathrm{BF}_{4}\right]$. This could probably be attributed to the slow thermal elimination of the ester bond. On the other hand, the mechanical properties, such as the tensile strength and tensile modulus, of the modified GO/DGEAC nanocomposites moderately increased by up to $4.3 \%$ and $4.0 \%$, respectively, compared to the unmodified GO/DGEAC nanocomposite. This was caused by the capability of the modified GO to disperse well in the DGEAC matrix and improve the interfacial bonding with the matrix. Additionally, the reinforcing ability of modified GO on the nanocomposites was well exerted compared to the pristine GO. Furthermore, the chemical properties, such as the D band, of the modified GO/DGEAC nanocomposites shifted to higher wavenumber regions in comparison to the $\mathrm{D}$ band of the unmodified GO/DGEAC nanocomposite. This was due to the exceptional interfacial bonding between the modified GO and DGEAC matrix [35]. Therefore, it can be deduced that the modification of $\mathrm{GO}$ with $[\mathrm{Bhpmim}]\left[\mathrm{BF}_{4}\right]$ ionic liquid provides DGEAC nanocomposites with moderate thermal and mechanical properties, as well as good interfacial bonding.

Meanwhile, GN modified with [Bmim] $\left[\mathrm{BF}_{4}\right]$ ionic liquid has been employed for the fabrication of [Bmim] $\left[\mathrm{BF}_{4}\right]$-modified GN/PI nanocomposites [39]. The thermal, mechanical, and chemical properties of the nanocomposites and their components were characterized by using differential scanning calorimeter, thermogravimetric analyzer, universal tensile tester, and Raman spectrometer. The thermal properties, such as the glass transition temperature, of the modified GN/PI nanocomposites moderately increased by up to $4.1 \%$ in comparison to the unmodified GN/PI nanocomposite. This was caused by the uniform dispersion of modified GN in the PI phase and strong adhesion to the polymer matrix, which restricted the movement of the molecular chains of PI during the glass phase transition, requiring more heat. Additionally, the initial decomposition temperature of the modified GN/PI nanocomposites increased by up to $9.2 \%$ compared to the unmodified GN/PI nanocomposite. This was because of the presence of $\pi-\pi$, cation- $\pi$, and van der Waals interactions between the $[\mathrm{Bmim}]\left[\mathrm{BF}_{4}\right]$ and $\mathrm{GN}$, which enhanced the dispersion of modified GN in the PI matrix. Consequently, the enhanced interfacial compatibility and stability of the modified GN with the matrix and the relaxation of the molecular chains of the PI required more fracture energy during the heating process. On top of that, the mechanical properties, such as the tensile strength and tensile modulus, of the modified GN/PI nanocomposites increased by up to $35 \%$ and $38 \%$, respectively, compared to the unmodified GN/PI nanocomposite. This was due to the outstanding dispersion and excessive degree of orientation of GN modified by $\left[\mathrm{Bmim}^{\mathrm{B}}\right]\left[\mathrm{BF}_{4}\right]$ in the polymer matrix, as well as the effective load transfer from PI to modified GN. Nonetheless, the elongation at break of the modified GN/PI nanocomposites decreased owing to the modified GN acted as a physical crosslinking agent, which restrained the flexibility of the PI molecular chains, subsequently increasing the brittleness of the nanocomposites, and preventing deformation. On the other hand, the chemical properties, such as the G band, of the modified GN shifted to a lower wavenumber region in comparison to the G band of the pristine GN. This was attributed to the modification of GN by [Bmim] $\left[\mathrm{BF}_{4}\right]$ affecting the lattice of GN [39]. Thus, it can be inferred that the modification of $\mathrm{GN}$ with $\left[\mathrm{Bmim}^{-}\left[\mathrm{BF}_{4}\right]\right.$ ionic liquid gives PI nanocomposites moderate thermal properties and high tensile strength and modulus properties, as well as good interaction.

Additionally, MWCNTs modified with $[\mathrm{Emim}]\left[\mathrm{BF}_{4}\right]$ ionic liquid have been employed for the fabrication of [Emim] $\left[\mathrm{BF}_{4}\right]$-modified MWCNT/EVM nanocomposites [40]. The thermal, mechanical, and chemical properties of the nanocomposites and their components were characterized by means of differential scanning calorimeter, thermogravimetric analyzer, tensile testing machine, and Raman spectrometer. The thermal properties, such as 
the glass transition temperature and melting temperature, of the modified MWCNT/EVM nanocomposites moderately increased by up to $2.2 \%$ and $6.2 \%$, respectively, compared to the unmodified MWCNT/EVM nanocomposite. This was attributed to the special interactions among MWCNTs, $[\mathrm{Emim}]\left[\mathrm{BF}_{4}\right]$, and EVM, which influenced the glass transition and melting temperatures of the nanocomposites. Nevertheless, the decomposition temperature remained almost unchanged for both of the nanocomposites. On the other hand, the mechanical properties, such as the tensile strength and elongation at break, of the modified MWCNT/EVM nanocomposites increased by up to $20 \%$ and $42 \%$, respectively, compared to the unmodified MWCNT/EVM nanocomposite. This was because of the reinforcing ability of the modified MWCNT and the plasticizing effect of [Emim] $\left[\mathrm{BF}_{4}\right]$ on the nanocomposites, which increased the strength, stretchability, and flexibility of the modified MWCNT/EVM nanocomposites. Furthermore, the chemical properties, such as the D band, of the modified MWCNT shifted to a higher wavenumber region in comparison to the D band of the pristine MWCNTs. This was caused by the formation of a strong interaction between the imidazolium ring of $[\mathrm{Emim}]\left[\mathrm{BF}_{4}\right]$ and the surface of MWCNTs through cation $-\pi$ or $\pi-\pi$ interactions [40]. Hence, it can be concluded that the modification of MWCNTs with [Emim] $\left[\mathrm{BF}_{4}\right]$ ionic liquid grants EVM nanocomposites moderate thermal properties and high tensile strength and elongation properties, as well as good interaction.

\subsection{Effect of Alkylimidazolium Bistriflimide Ionic Liquids}

MWCNTs modified with $\left[\mathrm{Bmim}_{[}\left[\mathrm{NTf}_{2}\right]\right.$ ionic liquid have been employed for the fabrication of [Bmim] [NTf 2 ]-modified MWCNT/CR nanocomposites [42]. The thermal, mechanical, and chemical properties of the nanocomposites and their components were characterized by using differential scanning calorimeter, thermogravimetric analyzer, universal testing machine, and Raman spectrometer. The thermal properties, such as the glass transition temperature of the modified MWCNT/CR nanocomposites, slightly increased by up to $2.6 \%$ compared to the unmodified MWCNT/CR nanocomposite (Table 5). This is probably due to the presence of specific interactions between the ionic liquid and nanofiller. Moreover, the maximum decomposition temperature of the [Bmim][NTf $\left.\mathrm{NT}_{2}\right]$ MWCNT increased by up to $5.2 \%$ compared to the pristine [Bmim] $\left.\mathrm{NTf}_{2}\right]$. This was attributed to the adhesion of [Bmim] $\left[\mathrm{NTf}_{2}\right]$ to $\mathrm{MWCNTs}$ via cation $-\pi, \pi-\pi$, or van der Waals interactions, which enhanced the thermal stability of [Bmim] $\left[\mathrm{NTf}_{2}\right]$. On top of that, the mechanical properties, such as the tensile modulus and hardness, of the modified MWCNT/CR nanocomposites increased by up to $48 \%$ and $2.7 \%$, respectively, compared to the unmodified MWCNT/CR nanocomposite. This was caused by the presence of [Bmim] $\left[\mathrm{NTf}_{2}\right]$, which acted as a coupling agent for the nanocomposites. In addition, the chemical properties, such as the G band, of the modified MWCNT/CR nanocomposite shifted to a higher wavenumber region in comparison to the $G$ band of the unmodified MWCNT/CR nanocomposite. This was because of the disentanglement of the modified MWCNT and subsequent dispersion in the matrix due to the penetration of the CR into the bundles of MWCNTs during the mixing process [42]. Therefore, it can be deduced that the modification of MWCNTs with [Bmim] $\left[\mathrm{NTf}_{2}\right]$ ionic liquid provides CR nanocomposites with moderate thermal properties and high tensile modulus, as well as good interaction.

Meanwhile, MWCNTs modified with [Bmim] $\left[\mathrm{NTf}_{2}\right]$ ionic liquid have been employed for the fabrication of [Bmim][NTf 2 -modified MWCNT/NRL nanocomposites [51]. The thermal, mechanical, and chemical properties of the nanocomposites and their components were characterized by means of differential scanning calorimeter, thermogravimetric analyzer, universal tensile testing machine, and FTIR spectrometer. The thermal properties, such as the glass transition temperature, of the modified MWCNT/NRL nanocomposites increased by up to $7.9 \%$ in comparison to the unmodified MWCNT/NRL nanocomposite. This was caused by the good interaction between the modified MWCNT and NRL, which promoted the formation of three-dimensional MWCNTs networks and restricted the movement or flexibility of the molecular chains of NRL. This also indicated the partial miscibility of the nanocomposite components. However, the decomposition temperature of 
the modified MWCNT/NRL nanocomposites decreased owing to the high thermal conductivity of MWCNTs and the low molecular weight of [Bmim][NTf $\left.{ }_{2}\right]$, which favored thermal decomposition of the nanocomposites. Furthermore, the mechanical properties, such as the tensile strength and elongation at break, of the modified MWCNT/NRL nanocomposites slightly decreased because of the small molecules of ionic liquid freely dispersed in the NRL matrix, which acted as defects that initiated failure. Nevertheless, the tensile modulus of the modified MWCNT/NRL nanocomposites increased by up to $73 \%$ compared to the unmodified MWCNT/NRL nanocomposite. This was attributed to the good dispersion of modified MWCNT, along with the formed MWCNTs networks in the matrix, assisted by interactions among ionic liquid, MWCNTs, and NRL. On the other hand, the chemical properties, such as the absorption band of the $\mathrm{C}-\mathrm{O}$ stretching vibration, of the modified MWCNT/NRL nanocomposite shifted to a lower wavenumber region in comparison to the $\mathrm{C}-\mathrm{O}$ stretching vibration of the unmodified MWCNT/NRL nanocomposite. This was due to the modified MWCNT bridging NRL and [Bmim] $\left[\mathrm{NTf}_{2}\right]$ through $\pi-\pi$ interactions in the nanocomposites [51]. Thus, it can be inferred that the modification of MWCNTs with [Bmim] $\left[\mathrm{NTf}_{2}\right]$ ionic liquid gives NRL nanocomposites high glass transition temperature and tensile modulus, as well as good interaction.

MWCNTs modified with [Emim][NTf 2 ionic liquid have been employed for the fabrication of [Emim][NTf 2$]$-modified MWCNT/PVDF nanocomposites [54]. The thermal, mechanical, and chemical properties of the nanocomposites and their components were characterized using differential scanning calorimeter, micro universal testing machine, and FTIR spectrometer. The thermal properties, such as the glass transition temperature and melting temperature, of the modified MWCNT/PVDF nanocomposites decreased, which was attributed to the miscibility between the ionic liquid and PVDF. Moreover, the plasticizing effect of [Emim][NTf 2 on the PVDF matrix also decreased the thermal properties of the nanocomposites. On top of that, the mechanical properties, such as the tensile strength and elongation at break, of the modified MWCNT/PVDF nanocomposites significantly increased by up to $85 \%$ and $133 \%$, respectively, compared to the unmodified MWCNT/PVDF nanocomposite. This was caused by the presence of [Emim] $\left[\mathrm{NTf}_{2}\right]$ provided the good dispersion of MWCNTs in the PVDF matrix, which further enhanced the structural properties of the nanocomposites. Additionally, the modified MWCNT/PVDF nanocomposites were less brittle, with improved strength and ductility properties compared to unmodified MWCNT/PVDF nanocomposite. Nonetheless, the tensile modulus of the modified MWCNT/PVDF nanocomposites slightly decreased owing to the simultaneous increase in strength and elongation properties that could marginally reduce the rigidity of the nanocomposites. On the other hand, the chemical properties, such as the absorption band of the $\mathrm{CH}-\mathrm{CF}-\mathrm{CH}$ stretching vibration, of the modified MWCNT/PVDF nanocomposites shifted to a higher wavenumber region in comparison to the $\mathrm{CH}-\mathrm{CF}-\mathrm{CH}$ stretching vibration of the unmodified MWCNT/PVDF nanocomposite. This was due to the formation of an interaction between the modified MWCNT and PVDF via electrostatic interaction [54]. Hence, it can be concluded that the modification of MWCNTs with [Emim] $\left[\mathrm{NTf}_{2}\right]$ ionic liquid grants PVDF nanocomposites high tensile strength and elongation properties, as well as good interaction.

\section{Conclusions}

Types of imidazolium-based ionic liquids, modification processes of nanofillers, and fabrication processes of ionic liquid-modified nanofiller/polymer nanocomposites were succinctly reviewed in this paper. The important properties, for example, thermal, mechanical, and chemical, of the nanocomposites were also described in this succinct review. Ionic liquids used for the modification of various types of nanofillers are mostly based on imidazolium cations combined with different counter anions. In addition, alkylimidazolium halide, alkylimidazolium hexafluorophosphate, alkylimidazolium tetrafluoroborate, and alkylimidazolium bistriflimide ionic liquids are the four most significant ionic liquids used for polymer nanocomposites. Alkylimidazolium halide ionic liquid is frequently employed 
in the modification of several types of nanofillers. Meanwhile, alkylimidazolium hexafluorophosphate, alkylimidazolium tetrafluoroborate, and alkylimidazolium bistriflimide ionic liquids are typically used in the modification of carbon-based nanofillers. The employment of ionic liquid-modified nanofillers can effectively improve the thermo-mechanico-chemical properties of polymer nanocomposites. Additionally, ionic liquid-modified nanofillers can form specific interactions with polymer matrices. Alkylimidazolium halide-modified nanofiller/polymer nanocomposites possess high mechanical properties and good interaction. On top of that, alkylimidazolium hexafluorophosphate-modified nanofiller/polymer nanocomposites exhibit high thermal and mechanical properties and good compatibility. Meanwhile, alkylimidazolium tetrafluoroborate-modified nanofiller/polymer nanocomposites demonstrate moderate thermal properties, high mechanical properties, and good interaction. Additionally, alkylimidazolium bistriflimide-modified nanofiller/polymer nanocomposites have moderate thermal properties, high mechanical properties, and good interaction. This succinct review may be valuable for the modification of nanofillers by using ionic liquids in the fabrication of polymer nanocomposites for a variety of usages.

Author Contributions: Conceptualization, A.A.S.; methodology, S.N.A.M.J.; validation, S.N.A.M.J. and K.A.; formal analysis, S.N.A.M.J.; investigation, A.A.S.; resources, K.A.; data curation, A.A.S.; writing-original draft preparation, A.A.S.; writing-review and editing, S.N.A.M.J.; project administration, K.A.; funding acquisition, K.A. All authors have read and agreed to the published version of the manuscript.

Funding: This succinct review was funded by the Universiti Putra Malaysia (vote number: 9001103).

Institutional Review Board Statement: Not applicable.

Informed Consent Statement: Not applicable.

Data Availability Statement: Not applicable.

Acknowledgments: The authors would like to thank M. Ali Aboudzadeh from the Centro de Física de Materiales, CSIC-UPV/EHU, and Shaghayegh Hamzehlou from the University of the Basque Country UPV-EHU for inviting the authors to write this succinct review.

Conflicts of Interest: The authors declare no conflict of interest. The funder had no role in the design of the review; in the collection, analyses, or interpretation of data; in the writing of the manuscript, or in the decision to publish the results.

\section{References}

1. Shamsuri, A.A.; Md Jamil, S.N.A. Compatibilization Effect of Ionic Liquid-Based Surfactants on Physicochemical Properties of PBS/Rice Starch Blends: An Initial Study. Materials 2020, 13, 1885. [CrossRef]

2. Shamsuri, A.A.; Md Jamil, S.N.A. Functional Properties of Biopolymer-Based Films Modified with Surfactants: A Brief Review. Processes 2020, 8, 1039. [CrossRef]

3. Shamsuri, A.A.; Daik, R. Mechanical and Thermal Properties of Nylon-6/LNR/MMT Nanocomposites Prepared Through Emulsion Dispersion Technique. J. Adv. Res. Fluid Mech. Therm. Sci. 2020, 73, 1-12. [CrossRef]

4. Prasad Sahoo, B.; Naskar, K.; Kumar Tripathy, D. Multiwalled carbon nanotube-filled ethylene acrylic elastomer nanocomposites: Influence of ionic liquids on the mechanical, dynamic mechanical, and dielectric properties. Polym. Compos. 2016, 37, 2568-2580. [CrossRef]

5. Zhang, X.; Xue, X.; Jia, H.; Wang, J.; Ji, Q.; Xu, Z. Influence of ionic liquid on the polymer-filler coupling and mechanical properties of nano-silica filled elastomer. J. Appl. Polym. Sci. 2017, 134, 44478. [CrossRef]

6. Yin, B.; Zhang, X.; Zhang, X.; Wang, J.; Wen, Y.; Jia, H.; Ji, Q.; Ding, L. Ionic liquid functionalized graphene oxide for enhancement of styrene-butadiene rubber nanocomposites. Polym. Adv. Technol. 2017, 28, 293-302. [CrossRef]

7. Sahu, G.; Tripathy, J.; Sahoo, B.P. Significant enhancement of dielectric properties of graphene oxide filled polyvinyl alcohol nanocomposites: Effect of ionic liquid and temperature. Polym. Compos. 2020, 41, 4411-4430. [CrossRef]

8. Qiu, M.; Zhang, B.; Wu, H.; Cao, L.; He, X.; Li, Y.; Li, J.; Xu, M.; Jiang, Z. Preparation of anion exchange membrane with enhanced conductivity and alkaline stability by incorporating ionic liquid modified carbon nanotubes. J. Memb. Sci. 2019, 573, 1-10. [CrossRef]

9. Huang, G.; Isfahani, A.P.; Muchtar, A.; Sakurai, K.; Shrestha, B.B.; Qin, D.; Yamaguchi, D.; Sivaniah, E.; Ghalei, B. Pebax/ionic liquid modified graphene oxide mixed matrix membranes for enhanced $\mathrm{CO}_{2}$ capture. J. Memb. Sci. 2018, 565, 370-379. [CrossRef] 
10. Thomas, E.; Parvathy, C.; Balachandran, N.; Bhuvaneswari, S.; Vijayalakshmi, K.P.; George, B.K. PVDF-ionic liquid modified clay nanocomposites: Phase changes and shish-kebab structure. Polymer 2017, 115, 70-76. [CrossRef]

11. Abraham, J.; Xavier, P.; Bose, S.; George, S.C.; Kalarikkal, N.; Thomas, S. Investigation into dielectric behaviour and electromagnetic interference shielding effectiveness of conducting styrene butadiene rubber composites containing ionic liquid modified MWCNT. Polymer 2017, 112, 102-115. [CrossRef]

12. Abraham, J.; Zachariah, A.K.; Wilson, R.; Ibarra-Gómez, R.; Muller, R.; George, S.C.; Kalarikkal, N.; Thomas, S. Effect of ionic liquid modified MWCNT on the rheological and microstructural developments in styrene butadiene rubber nanocomposites. Rubber Chem. Technol. 2019, 92, 531-545. [CrossRef]

13. Abraham, J.; Thomas, J.; Kalarikkal, N.; George, S.C.; Thomas, S. Static and Dynamic Mechanical Characteristics of Ionic Liquid Modified MWCNT-SBR Composites: Theoretical Perspectives for the Nanoscale Reinforcement Mechanism. J. Phys. Chem. B 2018, 122, 1525-1536. [CrossRef]

14. Abraham, J.; Jose, T.; Moni, G.; George, S.C.; Kalarikkal, N.; Thomas, S. Ionic liquid modified multiwalled carbon nanotube embedded styrene butadiene rubber membranes for the selective removal of toluene from toluene/methanol mixture via pervaporation. J. Taiwan Inst. Chem. Eng. 2019, 95, 594-601. [CrossRef]

15. George, S.; Abraham, J.; Jose, T.; Kalarikkal, N.; Thomas, S. Mechanics and Pervaporation Performance of Ionic Liquid Modified CNT Based SBR Membranes-A Case Study for the Separation of Toluene/Heptane Mixtures. Int. J. Membr. Sci. Technol. 2015, 2, 30-38. [CrossRef]

16. Abraham, J.; Sidhardhan Sisanth, K.; Zachariah, A.K.; Mariya, H.J.; George, S.C.; Kalarikkal, N.; Thomas, S. Transport and solvent sensing characteristics of styrene butadiene rubber nanocomposites containing imidazolium ionic liquid modified carbon nanotubes. J. Appl. Polym. Sci. 2020, 137, e49429. [CrossRef]

17. Sowińska, A.; Maciejewska, M.; Guo, L.; Delebecq, E. Effect of SILPs on the Vulcanization and Properties of Ethylene-PropyleneDiene Elastomer. Polymers 2020, 12, 1220. [CrossRef] [PubMed]

18. Le, H.H.; Wießner, S.; Das, A.; Fischer, D.; Auf Der Landwehr, M.; Do, Q.K.; Stöckelhuber, K.W.; Heinrich, G.; Radusch, H.J. Selective wetting of carbon nanotubes in rubber compounds-Effect of the ionic liquid as dispersing and coupling agent. Eur. Polym. J. 2016, 75, 13-24. [CrossRef]

19. Xu, P.; Cui, Z.P.; Ruan, G.; Ding, Y.S. Enhanced Crystallization Kinetics of PLLA by Ethoxycarbonyl Ionic Liquid Modified Graphene. Chin. J. Polym. Sci. 2019, 37, 243-252. [CrossRef]

20. Ge, Y.; Zhang, Q.; Zhang, Y.; Liu, F.; Han, J.; Wu, C. High-performance natural rubber latex composites developed by a green approach using ionic liquid-modified multiwalled carbon nanotubes. J. Appl. Polym. Sci. 2018, 135, 46588. [CrossRef]

21. Członka, S.; Strąkowska, A.; Strzelec, K.; Kairytè, A.; Kremensas, A. Melamine, silica, and ionic liquid as a novel flame retardant for rigid polyurethane foams with enhanced flame retardancy and mechanical properties. Polym. Test. 2020, 87, 106511. [CrossRef]

22. Bahader, A.; Haoguan, G.; HaoGoa, F.; Ping, W.; Shaojun, W.; Yunsheng, D. Preparation and characterization of poly(vinylidene fluoride) nanocomposites containing amphiphilic ionic liquid modified multiwalled carbon nanotubes. J. Polym. Res. 2016, 23, 184. [CrossRef]

23. Song, S.; Xia, S.; Liu, Y.; Lv, X.; Sun, S. Effect of Na+ MMT-ionic liquid synergy on electroactive, mechanical, dielectric and energy storage properties of transparent PVDF-based nanocomposites. Chem. Eng. J. 2020, 384, 123365. [CrossRef]

24. Shi, F.; Ma, Y.; Ma, J.; Wang, P.; Sun, W. Preparation and characterization of PVDF/ $\mathrm{TiO}_{2}$ hybrid membranes with ionic liquid modified nano-TiO2 particles. J. Memb. Sci. 2013, 427, 259-269. [CrossRef]

25. Pelit, F.O.; Pelit, L.; Dizdaş, T.N.; Aftafa, C.; Ertaş, H.; Yalçinkaya, E.E.; Türkmen, H.; Ertaş, F.N. A novel polythiophene-Ionic liquid modified clay composite solid phase microextraction fiber: Preparation, characterization and application to pesticide analysis. Anal. Chim. Acta 2015, 859, 37-45. [CrossRef]

26. Caldas, C.M.; Soares, B.G.; Indrusiak, T.; Barra, G.M.O. Ionic liquids as dispersing agents of graphene nanoplatelets in poly(methyl methacrylate) composites with microwave absorbing properties. J. Appl. Polym. Sci. 2021, 138, e49814. [CrossRef]

27. Mondal, T.; Basak, S.; Bhowmick, A.K. Ionic liquid modification of graphene oxide and its role towards controlling the porosity, and mechanical robustness of polyurethane foam. Polymer 2017, 127, 106-118. [CrossRef]

28. Chen, G.X.; Zhang, S.; Zhou, Z.; Li, Q. Dielectric properties of poly(vinylidene fluoride) composites based on bucky gels of carbon nanotubes with ionic liquids. Polym. Compos. 2015, 36, 94-101. [CrossRef]

29. Xiong, X.; Wang, J.; Jia, H.; Fang, E.; Ding, L. Structure, thermal conductivity, and thermal stability of bromobutyl rubber nanocomposites with ionic liquid modified graphene oxide. Polym. Degrad. Stab. 2013, 98, 2208-2214. [CrossRef]

30. Ke, K.; Pötschke, P.; Gao, S.; Voit, B. An Ionic Liquid as Interface Linker for Tuning Piezoresistive Sensitivity and Toughness in Poly(vinylidene fluoride)/Carbon Nanotube Composites. ACS Appl. Mater. Interfaces 2017, 9, 5437-5446. [CrossRef]

31. Członka, S.; Strakowska, A.; Strzelec, K.; Kairytè, A.; Vaitkus, S. Composites of rigid polyurethane foams and silica powder filler enhanced with ionic liquid. Polym. Test. 2019, 75, 12-25. [CrossRef]

32. Chen, Y.; Tao, J.; Deng, L.; Li, L.; Li, J.; Yang, Y.; Khashab, N.M. Polyetherimide/bucky gels nanocomposites with superior conductivity and thermal stability. ACS Appl. Mater. Interfaces 2013, 5, 7478-7484. [CrossRef]

33. Zheng, X.; Li, D.; Feng, C.; Chen, X. Thermal properties and non-isothermal curing kinetics of carbon nanotubes/ionic liquid/epoxy resin systems. Thermochim. Acta 2015, 618, 18-25. [CrossRef]

34. Fang, D.; Zhou, C.; Liu, G.; Luo, G.; Gong, P.; Yang, Q.; Niu, Y.; Li, G. Effects of ionic liquids and thermal annealing on the rheological behavior and electrical properties of poly(methyl methacrylate)/carbon nanotubes composites. Polymer 2018, 148, 68-78. [CrossRef] 
35. Shi, K.; Luo, J.; Huan, X.; Lin, S.; Liu, X.; Jia, X.; Zu, L.; Cai, Q.; Yang, X. Ionic Liquid-Graphene Oxide for Strengthening Microwave Curing Epoxy Composites. ACS Appl. Nano Mater. 2020, 3, 11955-11969. [CrossRef]

36. Damlin, P.; Suominen, M.; Heinonen, M.; Kvarnström, C. Non-covalent modification of graphene sheets in PEDOT composite materials by ionic liquids. Carbon N. Y. 2015, 93, 533-543. [CrossRef]

37. Lopes Pereira, E.C.; Soares, B.G. Conducting epoxy networks modified with non-covalently functionalized multi-walled carbon nanotube with imidazolium-based ionic liquid. J. Appl. Polym. Sci. 2016, 133, 43976. [CrossRef]

38. Rhyu, S.Y.; Cho, Y.; Kang, S.W. Nanocomposite membranes consisting of poly(ethylene oxide)/ionic liquid $/ \mathrm{ZnO}_{\text {for }} \mathrm{CO}_{2}$ separation. J. Ind. Eng. Chem. 2020, 85, 75-80. [CrossRef]

39. Ruan, H.; Zhang, Q.; Liao, W.; Li, Y.; Huang, X.; Xu, X.; Lu, S. Enhancing tribological, mechanical, and thermal properties of polyimide composites by the synergistic effect between graphene and ionic liquid. Mater. Des. 2020, 189, 108527. [CrossRef]

40. Cao, X.; Jin, M.; Liang, Y.; Li, Y. Synergistic effects of two types of ionic liquids on the dispersion of multiwalled carbon nanotubes in ethylene-vinyl acetate elastomer: Preparation and characterization of flexible conductive composites. Polym. Int. 2017, 66, 1708-1715. [CrossRef]

41. Xing, C.; Wang, Y.; Huang, X.; Li, Y.; Li, J. Poly(vinylidene fluoride) Nanocomposites with Simultaneous Organic Nanodomains and Inorganic Nanoparticles. Macromolecules 2016, 49, 1026-1035. [CrossRef]

42. Subramaniam, K.; Das, A.; Steinhauser, D.; Klüppel, M.; Heinrich, G. Effect of ionic liquid on dielectric, mechanical and dynamic mechanical properties of multi-walled carbon nanotubes/polychloroprene rubber composites. Eur. Polym. J. 2011, 47, $2234-2243$. [CrossRef]

43. Subramaniam, K.; Das, A.; Heinrich, G. Development of conducting polychloroprene rubber using imidazolium based ionic liquid modified multi-walled carbon nanotubes. Compos. Sci. Technol. 2011, 71, 1441-1449. [CrossRef]

44. Subramaniam, K.; Das, A.; Häußler, L.; Harnisch, C.; Stöckelhuber, K.W.; Heinrich, G. Enhanced thermal stability of polychloroprene rubber composites with ionic liquid modified MWCNTs. Polym. Degrad. Stab. 2012, 97, 776-785. [CrossRef]

45. Subramaniam, K.; Das, A.; Simon, F.; Heinrich, G. Networking of ionic liquid modified CNTs in SSBR. Eur. Polym. J. 2013, 49, 345-352. [CrossRef]

46. Subramaniam, K.; Das, A.; Heinrich, G. Highly conducting polychloroprene composites based on multi-walled carbon nanotubes and 1-butyl 3-methyl imidazolium bis(trifluoromethylsulphonyl)imide. KGK Kautsch. Gummi Kunstst. 2012, 65, 44-46.

47. Steinhauser, D.; Subramaniam, K.; Das, A.; Heinrich, G.; Klüppel, M. Influence of ionic liquids on the dielectric relaxation behavior of CNT based elastomer nanocomposites. Express Polym. Lett. 2012, 6, 927-936. [CrossRef]

48. Le, H.H.; Hoang, X.T.; Das, A.; Gohs, U.; Stoeckelhuber, K.W.; Boldt, R.; Heinrich, G.; Adhikari, R.; Radusch, H.J. Kinetics of filler wetting and dispersion in carbon nanotube/rubber composites. Carbon N. Y. 2012, 50, 4543-4556. [CrossRef]

49. Subramaniam, K.; Das, A.; Heinrich, G. Improved oxidation resistance of conducting polychloroprene composites. Compos. Sci. Technol. 2013, 74, 14-19. [CrossRef]

50. Semeriyanov, F.F.; Chervanyov, A.I.; Jurk, R.; Subramaniam, K.; König, S.; Roscher, M.; Das, A.; Stöckelhuber, K.W.; Heinrich, G. Non-monotonic dependence of the conductivity of carbon nanotube-filled elastomers subjected to uniaxial compression/decompression. J. Appl. Phys. 2013, 113, 103706. [CrossRef]

51. Krainoi, A.; Kummerlöwe, C.; Nakaramontri, Y.; Wisunthorn, S.; Vennemann, N.; Pichaiyut, S.; Kiatkamjornwong, S.; Nakason, C. Influence of carbon nanotube and ionic liquid on properties of natural rubber nanocomposites. Express Polym. Lett. 2019, 13, 327-348. [CrossRef]

52. Jiang, G.; Song, S.; Zhai, Y.; Feng, C.; Zhang, Y. Improving the filler dispersion of polychloroprene/carboxylated multi-walled carbon nanotubes composites by non-covalent functionalization of carboxylated ionic liquid. Compos. Sci. Technol. 2016, 123, 171-178. [CrossRef]

53. Abraham, J.; Mohammed Arif, P.; Kailas, L.; Kalarikkal, N.; George, S.C.; Thomas, S. Developing highly conducting and mechanically durable styrene butadiene rubber composites with tailored microstructural properties by a green approach using ionic liquid modified MWCNTs. RSC Adv. 2016, 6, 32493. [CrossRef]

54. Sharma, M.; Sharma, S.; Abraham, J.; Thomas, S.; Madras, G.; Bose, S. Flexible EMI shielding materials derived by melt blending PVDF and ionic liquid modified MWNTs. Mater. Res. Express 2014, 1, 035003. [CrossRef]

55. Hassouneh, S.S.; Yu, L.; Skov, A.L.; Daugaard, A.E. Soft and flexible conductive PDMS/MWCNT composites. J. Appl. Polym. Sci. 2017, 134, 44767. [CrossRef]

56. Shamsuri, A.A.; Jamil, S.N.A.M. A Short Review on the Effect of Surfactants on the Mechanico-Thermal Properties of Polymer Nanocomposites. Appl. Sci. 2020, 10, 4867. [CrossRef]

57. Shamsuri, A.A.; Abdullah, D.K. Protonation and Complexation Approaches for Production of Protic Eutectic Ionic Liquids. J. Phys. Sci. 2010, 21, 15-28.

58. Shamsuri, A.A.; Abdan, K.; Kaneko, T. A Concise Review on the Physicochemical Properties of Biopolymer Blends Prepared in Ionic Liquids. Molecules 2021, 26, 216. [CrossRef]

59. Shamsuri, A.A.; Abdullah, D.K. Synthesizing of ionic liquids from different chemical pathways. Int. J. Appl. Chem. 2011, 7, 15-24.

60. Hassanshahi, N.; Hu, G.; Li, J. Application of Ionic Liquids for Chemical Demulsification: A Review. Molecules 2020, $25,4915$. [CrossRef] 